\title{
Perancangan Signage pada Kawasan Wisata Exotic Mengare di Kabupaten Gresik
}

\author{
Nur Adilah Luthfiyyatur Rohmah, Didit Prasetyo, dan Naufan Noordyanto \\ Departemen Desain Komunikasi Visual, Fakultas Desain Kreatif dan Bisnis Digital, \\ Institut Teknologi Sepuluh Nopember \\ Surabaya, Indonesia \\ e-mail: nuradilahlr@gmail.com
}

\begin{abstract}
Abstrak-Exotic Mengare merupakan objek wisata alam dan bernilai sejarah dari Kabupaten Gresik. Seiring bertambahnya tahun, wisatawan yang berdatangan terus meningkat begitu juga dengan intensitas pergerakan dalam kawasan objek wisata tidak diimbangi dengan fasilitas sign system yang informatif. Sehingga didalam perjalanan, ditemukan beberapa pengunjung yang tersesat dan kebingungan. Tujuan perancangan ini adalah menciptakan signage pada Exotic Mengare untuk mengoptimalkan kualitas pengalaman wisatawan yang berkunjung dan memudahkan wisatawan mendapatkan informasi dalam bentuk komunikasi visual.Perancangan signage pada ini disusun dengan menggunakan metode kualitatif yang diperolah dari depth interview, dan user persona dalam proses mengumpulkan informasi dan menganalisis data. Desain konsep yang dihasilkan dari perancangan ini menyesuaikan dengan konten objek wisata, yakni mengusung kesan dari unsur alam dan diadaptasi dari elemen sekitar dengan menggunakan font, material, konten informasi dan bahasa yang sesuai dengan kondisi lingkungan Pulau Mengare. Luaran dari perancangan ini meliputi signage peta wisata, directional sign serta signage peringatan berupa visualisasi desain digital untuk Exotic Mengare. Diharapkan dari penelitian yang dihasilkan bermanfaat untuk Pulau Mengare supaya lebih dikenal masyarakat sekitar.
\end{abstract}

Kata Kunci-exotic mengare, alami, signage, wisata

Abstract-Exotic Mengare is a natural and historical tourism object from Gresik Regency. As the years go by, the tourists who arrive continue to increase as well as the intensity of movement within the tourist attraction area is not matched by an informative sign system facility. So that on the way, some visitors were found lost and confused. The purpose of this design is to create signage on Exotic Mengare to optimize the quality of the experience of tourists visiting and make it easier for tourists to get information in the form of visual communication. The design of this signage is prepared using qualitative methods obtained from depth interviews, and user personas in the process of gathering information and analyzing data. The concept design resulting from this design adapts to the content of the tourist attraction, which carries the impression impression of natural elements and is adapted from the surrounding elements by using fonts, materials, information content and language that are in accordance with the environmental conditions of Mengare Island. The output of this design includes tourist map signage, directional signs and warning signage in the form of visualizing digital designs for Exotic Mengare. It is hoped that the resulting research will be useful for Mengare Island so that it will be better known to the surrounding community.

Keywords-exotic mengare, nature, signage, tourism

\section{PENDAHULUAN}

Pulau Mengare merupakan salah satu pulau di Kabupaten Gresik yang berbatasan dengan kecamatan Manyar di sebelah selatan, sungai Kramat di sebelah barat, selat Madura di sebelah timur, dan sungai Cemara di sebelah Utara [1]. Pulau Mengare memiliki sedimentasi keanekaragaman, mulai dari keindahan alam, sejarah, hingga budaya. Di dalamnya juga terdapat salah satu alternatif objek wisata alam dan heritage yakni Exotic Mengare. Objek wisata ini dibuka sejak Juli tahun 2017 dan dikelola oleh volunteer yang berasal dari luar daerah Mengare. Beberapa fasilitas yang disajikan dalam objek wisata alam meliputi hutan, bakau, pantai pasir putih, benteng Lodewijk, dan lokasi yang bisa digunakan untuk camping maupun spot memancing [2]. Berdasarkan informasi yang didapatkan dari anggota Konversi Tim Kerja Pengembangan Pariwisata Exotic Mengare, dengan sedemikian banyaknya pesona wisata yang disajikan pada Exotic Mengare membuat wisatawan yang datang terus meningkat setiap tahunnya. Pengunjung yang datang didominasi oleh warga Gresik dan sekitarnya.

Tujuan awal didirikannya sebagai objek wisata adalah sebagai sarana edukasi penyatuan manusia untuk lebih dekat dengan alam, dan belajar sejarah, Selain untuk tujuan tersebut, tim volunteer juga mendirikan warung di dalam lokasi objek wisata sebagai penunjang ekonomi istri para petani tambak sekitar yang tidak bekerja (Gambar 1).

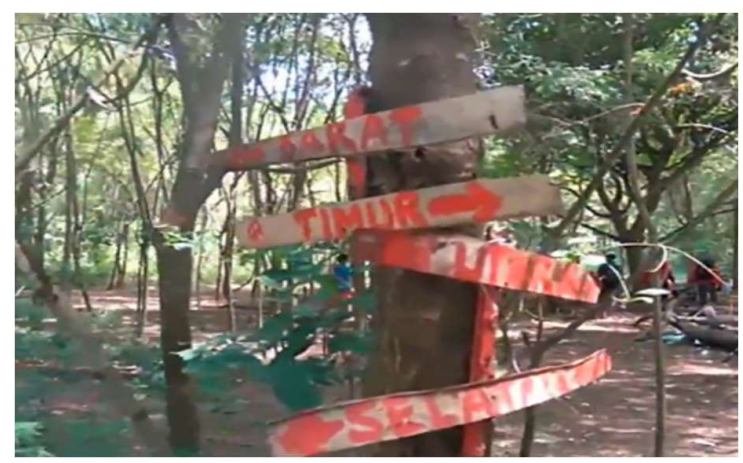

Gambar 1. Signage pada Exotic Mengare. Sumber: youtube.com 


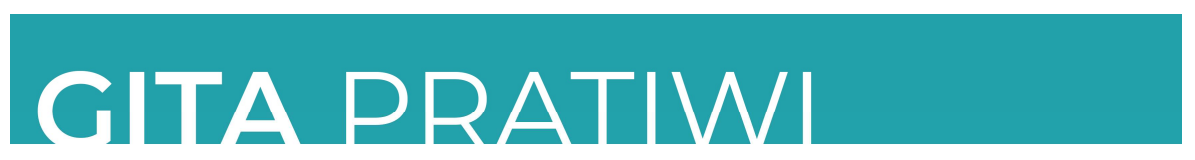

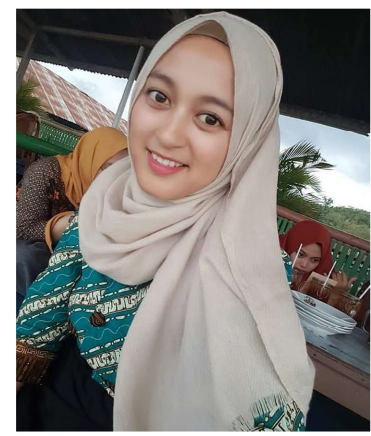

AGE 24

STATUS Single

OCCUPATION Akuntan

LOCATION Gresik
BIO

Gita adalah Akuntan yang tinggal di Gresik. la gemar melakukan travelling bersama teman dan keluarganya. Objek wisata bernuansa alam merupawa

\section{GOALS}

- Dia membutuhkan signage yang jelas ketika berada di ojek wisata. Memanfaatkan fasilitas yan diberikan.

ktu bersama teman dan keluarga.

\section{FRUSTRATIONS}

Gita seorang introvert yang malu bertanya di tempat umum. Mudah resah dan takut tersesat di tempat baru. Informasi minim pada sebuah

\section{MOTIVATIONS}

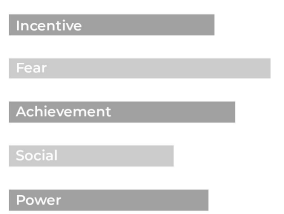

PERSONALITY

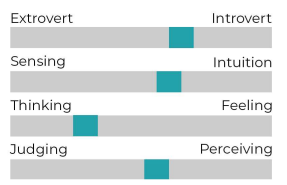

Gambar 2. User Persona.

Luasnya wilayah geografis pada Exotic Mengare menjadikan wisatawan membutuhkan media informasi seputar objek wisata yang dapat memandu dalam kegiatan berwisata. Exotic Mengare memiliki signage sebagai salah satu fasilitas pelayanan yang disediakan oleh pihak pengelola untuk pengunjung. Signage adalah sejenis visual grafis dalam ukuran besar yang dibuat untuk menyampaikan informasi pada kalangan audience tertentu. Signage sebelumnya dikenal dalam bentuk tanda (sign) atau dalam bentuk aksara, seperti petunjuk arah tempat, nama suatu tempat dan sebagainya [3], Signage yang baik harus mudah dibaca, dimengerti, dilihat, dan dapat dipercaya [4]. Penempatan letak signage yang tepat juga diperlukan untuk membuat pengunjung puas serta efisiensi waktu dan tenaga. Selain letak penempatan, warna juga harus diperhatikan dalam pembuatan signage pada lokasi objek wisata [5].

Pada objek wisata Exotic Mengare signange yang terdapat masih belum memenuhi standar. Adapun kondisinya berupa penempatan sign yang tidak tepat sehingga sign tidak terlihat oleh wisatawan dan sering diabaikan, berukuran kecil, minim informasi, warna yang tidak mencolok di beberapa lokasi, dan masih belum terdapat sign peringatan di kawasan camping ground karena terdapat kera liar yang bisa kapan saja mengambil barang wisatawan. Sehingga dari permasalahan komunikasi visual tersebut dampak yang ditimbulkan adalah; pengunjung kesulitan mencari dan mengetahui fasilitas yang berada di lokasi objek wisata terutama bagi pengunjung yang baru pertama kali berkunjung, pengunjung bisa tersesat, kebingungan, hingga dampak pada psikologis yang membuatnya menjadi merasa tidak aman ketika berwisata. Oleh karena itu, perancangan signage pada Exotic Mengare diadakan untuk menyelesaikan permasalahan yang dijelaskan sebelumnya dengan tujuan memudahkan wisatawan mendapatkan informasi mengenai tempat dan fasilitas yang disediakan, serta meningkatkan kualitas pengalaman pengunjung.

Berdasarkan latar belakang yang telah diuraikan sebelumnya, maka rumusan masalah yang diperoleh:
"Bagaimana merancang signage sebagai alat penunjuk arah untuk memudahkan wisatawan dalam mencari informasi dan fasilitas pada objek wisata Exotic Mengare di Kabupaten Gresik?"

Adapun batasan masalah dalam perancangan yang dilakukan agar dapat menghasilkan desain yang tepat dan komunikatif. Perancangan ini hanya berfokus pada pembuatan visualisasi desain signage di dalam objek wisata Kawasan Exotic Mengare. Adapun beberapa signage yang akan dibuat adalah penunjuk arah (directional sign) dengan jenis free-standing sign, infografis peta wisata mengenai lokasi dan fasilitas objek wisata Exotic Mengare, dan animal safety sign. Sementara hal yang berada di luar itu seperti signage rute jalan menuju ke lokasi objek wisata Exotic Mengare dan lain sebagainya bisa dilanjutkan pada penelitian selanjutnya.

\section{METODE PENELITIAN}

Dalam membuat sebuah desain, metode penelitian perlu dilakukan untuk menganalisa permasalahan yang ada agar desain yang dibuat sesuai dengan data yang didapatkan [6]. Pada perancangan signage pada objek wisata Exotic Mengare ini, proses pengumpulan data dilakukan menggunakan metode kualitatif. Hal ini bertujuan agar mendapatkan informasi secara langsung dari pihak pengelola objek wisata terutama mengenai signage yang ada pada lokasi wisata Exotic Mengare. Beberapa metode yang digunakan pada proses pengumpulan data ini adalah; Pertama, metode depth interview yang dilakukan pada 17 November pukul 19:07 WIB secara online dengan aplikasi WhatsApp sebagai media instrumentasi kepada Mas Yusuf Efendi selaku Anggota Tim Kerja Pengembangan Pariwisata Exotic Mengare. Wawancara ini bertujuan untuk mendapatkan informasi mengenai Exotic Mengare dan fokus terhadap signage apa saja yang ada pada objek wisata tersebut. Wawancara dilakukan menggunakan teknik semistruktur dengan 
menyiapkan beberapa pertanyaan yang diperlukan dan jika terdapat pertanyaan lain dapat diajukan secara langsung kepada narasumber.

Wawancara kepada beberapa narasumber yang pernah mengunjungi objek wisata Exotic Mengare juga dilakukan untuk mendapatkan kesan dan pendapat dari pengalaman mereka terkait signage dan informasi fasilitas yang ada. Berdasarkan hasil wawancara, dapat disimpulkan bahwa masih terdapat banyak hal yang perlu diperhatikan ketika merancang sebuah signage, seperti lokasi penempatan, material, dan jarak pandang. Sehingga dalam penyusunan sebuah signage sebaiknya disesuaikan dengan kondisi lokasi yang bersangkutan.

Kedua, metode user persona yang didapatkan dari penggabungan hasil interview dari beberapa narasumber dengan membuat persona fiksi yang mengacu dari hasil analisis untuk membantu mengetahui kebutuhan wisatawan [7]. Seperti yang sudah dijelaskan pada gambar 2 dimana hasil yang didapatkan dari user persona adalah Gita merupakan seorang Akuntan yang gemar melakukan travelling. Ia seorang introvert, mudah resah, dan takut bertanya. Gita sering memanfaatkan signage yang ada pada objek wisata untuk mendapatkan informasi mengenai tempat dan fasilitas yang ada. Gita membutuhkan signage yang informatif, mudah dipahami, tidak membingungkan, dan terlihat dengan jelas, seperti dapat dilihat pada Gambar 2.

Proses selanjutnya adalah melakukan analisis $5 \mathrm{~W}+1 \mathrm{H}$ dengan menjawab pertanyaan Apa (what), Dimana (where), Siapa (who), Mengapa (why), Kapan (when), Bagaimana (why). Dalam proses perancangan yang baik, perlu adanya pertanyaan yang perlu dijawab dan dipertimbangkan dengan menjelaskan permasalahan apa yang ditemukan dan dibahas (what), dimana perancangan ini dilakukan (where), siapa target audiens dari perancangan yang dibuat (who), mengapa perancangan ini harus dibuat (why), kapan perancangan ini dilakukan (when), dan bagaimana cara merancangnya (how).

\section{PEMBAHASAN}

\section{Konsep Desain}

Dalam perancangan ini konsep desain harus sesuai dengan tujuan signage yang akan dibuat dan digunakan, yaitu untuk mempermudah wisatawan mendapatkan informasi mengenai objek wisata dan fasilitas kawasan Exotic Mengare, mencegah wisatawan tersesat dan memperingatkan akan adanya hewan liar didalam kawasan sehingga wisatawan yang berkunjung dapat menikmati fasilitas yang ada dengan maksimal, aman, dan nyaman. Konsep desain yang digunakan diambil dari pertimbangan kondisi alam lokasi wisata yang masih alami [8]. Kondisi tersebut memberikan nuansa segar dan alami dengan warna hijau dan kuning yang menjadi dominan. Untuk itu, konsep desain signage pada Exotic Mengare ini menggunakan konsep natural yang diadaptasi dari elemen yang ada di sekitar lokasi wisata.

\section{Kriteria Desain}

1. Bentuk Signage

Bentuk signage pada perancangan ini dibuat seefektif dan semenarik mungkin dengan tetap memegang peraturan signage universal [9]. Diharapkan dari bentuk tersebut signage tidak hanya sebagai papan informasi tetapi juga sebagai elemen yang menambah estetika pada objek wosata tersebut.

\section{Ilustrasi}

Ilustrasi dalam perancangan signage ini digunakan sebagai pelengkap teks pada infografis peta wisata agar informasi yang diberikan semakin jelas. Gaya ilustrasi yang akan dibuat menerapkan clear and simple agar mudah dilihat.

\section{Warna}

Warna merupakan salah satu elemen visual yang dapat menarik perhatian pembaca. Apabila dalam pemilihan dan pemakaian dalam warna salah, dapat mengurangi ketertarikan pembaca [10]. Sehingga, pemilihan warna perlu diperhatikan karena memiliki pengaruh dalam menyampaikan pesan. Penetapan warna diambil dari identitas visual yang telah berlaku adanya [11]. Dalam perancangan signage menggunakan beberapa warna, seperti dapat dilihat pada Gambar 3.

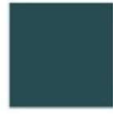

$C: 84$

$M: 55$

$\mathrm{Y}: 55$

$\mathrm{K}: 37$

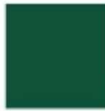

C: 88

$M: 41$

$Y: 81$

K: 41

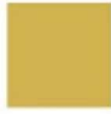

$\mathrm{C}: 20$

$M: 26$

$\mathrm{Y}: 82$

$\mathrm{K}: 0$

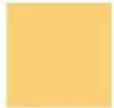

C: 2

$M: 18$

$\mathrm{Y}: 64$

$\mathrm{K}: 0$

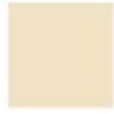

C: 5

$M: 9$

$Y: 25$

$\mathrm{K}: 0$
Gambar 3. Warna signage.

Jost

in|ExtraLighi|Light|Regular|Medium|SemiBold|BoldExtraBold|Black

ABCDEFGHIJKLMNOPQRSUVWXYZ

abcdefghijklmnopqrsturwxyz

1234567890

!@\#\$\%^**()

Gambar 4. Typeface 1.

\section{SERIES ORBIT \\ ABCDEF GHI JKLMNOPQR SUVWXYZ ABCDEF GHI JKLMNOPQR STUVWXYZ 1234567890 !田 $\$ \%+{ }^{*}()$}

Gambar 5. Typeface 2.

4. Tipografi

Typeface yang diterapkan pada perancangan ini menggunakan dua jenis font yaitu, sans serif dan script (Gambar-gamabr 4 dan 5). Jenis script dipilih karena memiliki bentuk yang khas, luwes dan tidak terkesan kaku. Sedangkan jenis sans serif digunakan untuk mendukung keterbacaan karena tidak memiliki kait dan secara kontur hurufnya lebih modern dan tegas, dibanding huruf serif [12].

\section{Proses Perancangan}

Tahap awal yang dilakukan dalam perancangan ini adalah dengan membuat sketsa awal. Sketsa ini dibuat secara digital menggunakan software Adobe Photoshop sebagai paduan dan 
ada 3 alternatif desain signage yang mana dari alternatif tersebut akan dipilih yang terbaik [13]. Seperti dapat dilihat pada Gambar-gambar 6, 7, dan 8 .

\section{Thumbnail Sketch}

Directional Signage
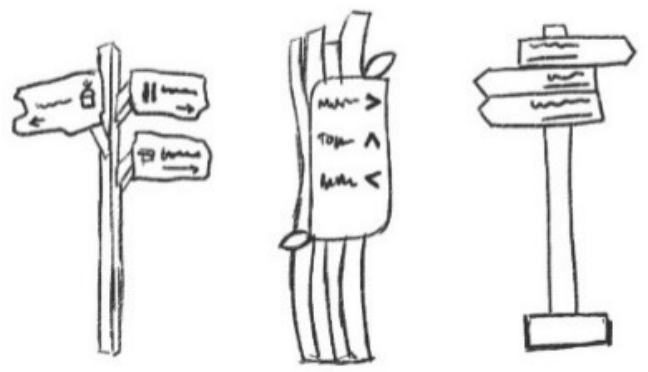

Gambar 6. Thumbnail Directional Signage.

Peta Wisata
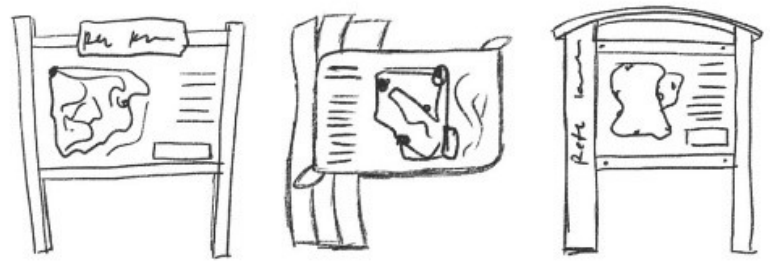

Gambar 7. Thumbnail Peta Kawasan
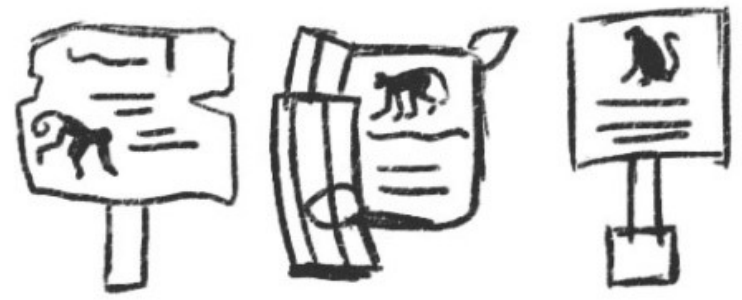

Gambar 8. Thumbnail Safety Signage.
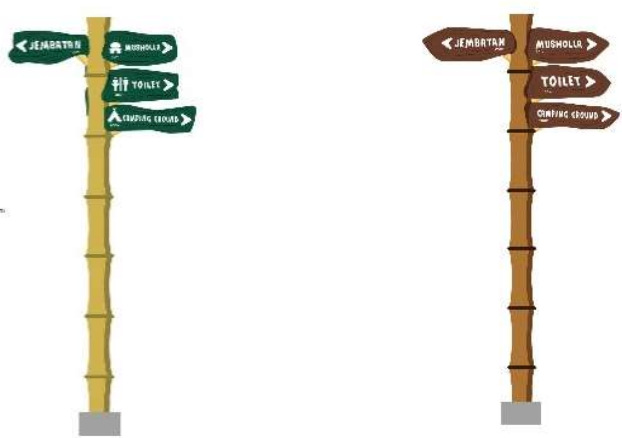

Gambar 9. Thight Issue Directional Sign.

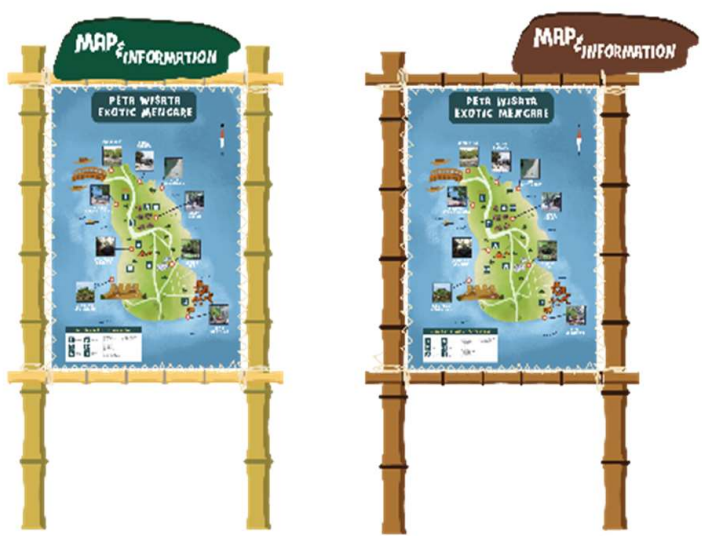

Gambar 10. Thight Issue Peta Wisata
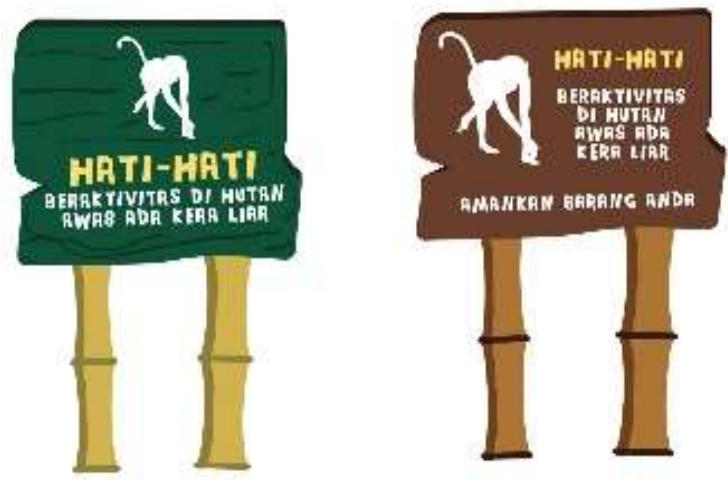

Gambar 11. Thight Issue Animal Safety Sign.

\section{Tight Issue}

Tahap kedua dilanjutkan melakukan proses pewarnaan secara digitalisasi. Dari tiga alternatif desain yang telah dibuat sebelumnya desain thumbnail yang dipilih adalah nomer satu karena dengan model tersebut bisa menyelaraskan signage yang sudah ada sebelumnya. Kemudian dibuat beberapa alternatif desain pada unsur komposisi dan warna, seperti dapat dilihat pada Gambargambar 9, 10, dan 11 .

3. Desain final

Directional Sign (Gambar 12).

Uraian berikut merupakan hasil dari desain final directional signage beserta spesifikasi untuk implementasi desain.

\begin{tabular}{|c|c|c|}
\hline Bahan/media & $\cdot$ & $\begin{array}{l}\text { Bambu petung, semen, } \\
\text { plat kayu, bambu cendani }\end{array}$ \\
\hline Ukuran & & $\begin{array}{l}190 \mathrm{~cm} \times 12 \mathrm{~cm} \text { (Bambu) } \\
15 \mathrm{~cm} \times 40-50 \mathrm{~cm} \text { (Plat) }\end{array}$ \\
\hline Tipografi & & Series Orbit \\
\hline Warna & & Kuning, hijau \\
\hline Lokasi & & \\
\hline pemasangan & & $\begin{array}{l}\text { Di depan arah masuk, dan } \\
\text { di setiap persimpangan }\end{array}$ \\
\hline Visualisasi & & Adobe Photoshop \& \\
\hline
\end{tabular}


Keterangan : Illustrator

Pondasi semen, plat kayu di paku dan disambung dengan bambo cendani

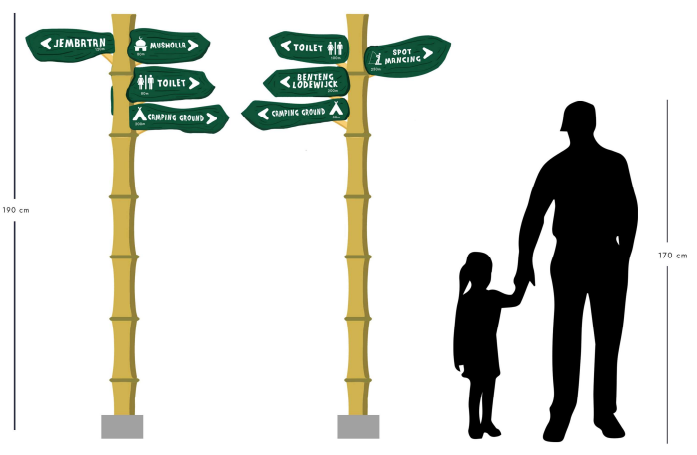

Gambar 12. Desain final Directional Sign.

Peta Wisata (Gambar 13).

Uraian berikut merupakan hasil dari desain final peta wisata beserta spesifikasi untuk implementasi desain.
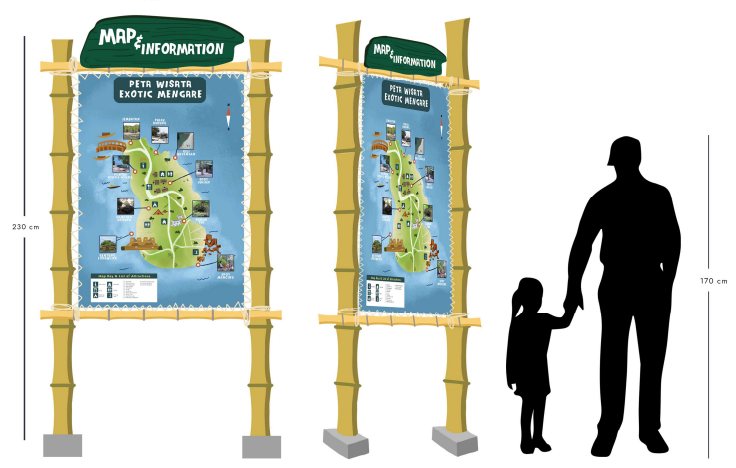

Gambar 13. Desain final Peta Wisata.

\begin{tabular}{|c|c|c|}
\hline Bahan/media & & $\begin{array}{l}\text { Bambu petung, semen } \\
\text { plat kayu, bamboo } \\
\text { cendani,banner, tali nilon }\end{array}$ \\
\hline Ukuran & : & $\begin{array}{l}230 \mathrm{~cm} \times 14 \mathrm{~cm} \text { (Bambu) } \\
22 \mathrm{~cm} \times 75 \mathrm{~cm} \text { (Plat) } \\
130 \mathrm{~cm} \times 80 \mathrm{~cm} \text { (banner) }\end{array}$ \\
\hline Tipografi & : & Series Orbit, Jost \\
\hline Warna & : & Kuning, hijau \\
\hline $\begin{array}{l}\text { Lokasi } \\
\text { pemasangan }\end{array}$ & : & $\begin{array}{l}\text { Area pintu masuk dan di } \\
\text { depan pohon }\end{array}$ \\
\hline Visualisasi & . & Adobe Photoshop \& Illustrator \\
\hline Keterangan & & $\begin{array}{l}\text { Plat kayu dipasang pada bambu } \\
\text { cendani dengan dipaku, } \\
\text { kemudian banner dilubangi dan } \\
\text { diikatkan ke bambu dengan tali } \\
\text { nilon berbentuk zigzag }\end{array}$ \\
\hline
\end{tabular}

selanjutnya diberi pondasi semen agar kuat.

Animal Safety Signage (Gambar 14)

Uraian berikut merupakan hasil dari desain final animal safety sign beserta spesifikasi untuk pengaplikasian desain.

$\begin{array}{lll}\text { Bahan/media } & : & \text { Bambu petung, plat kayu } \\ \text { Ukuran } & : & 60 \mathrm{~cm} \times 10 \mathrm{~cm} \text { (Bambu) } \\ & 40 \mathrm{~cm} \times 52 \mathrm{~cm} \text { (Plat) } \\ \text { Tipografi } & : & \begin{array}{l}\text { Series Orbit } \\ \text { Warna }\end{array} \\ \text { Lokasi } & : & \text { Kuning, hijau } \\ \text { pemasangan } & : & \begin{array}{l}\text { Kawasan Camping Ground, } \\ \text { Sumur Tua, dan Benteng } \\ \text { Adobe Photoshop \& }\end{array} \\ \text { Visualisasi } & : & \begin{array}{l}\text { Illustrator } \\ \text { Bambu dibelah menjadi dua } \\ \text { kemudian di paku pada plat, } \\ \text { signage ditanamkan pada } \\ \text { Keterangan }\end{array} \\ & \text { tanah }\end{array}$

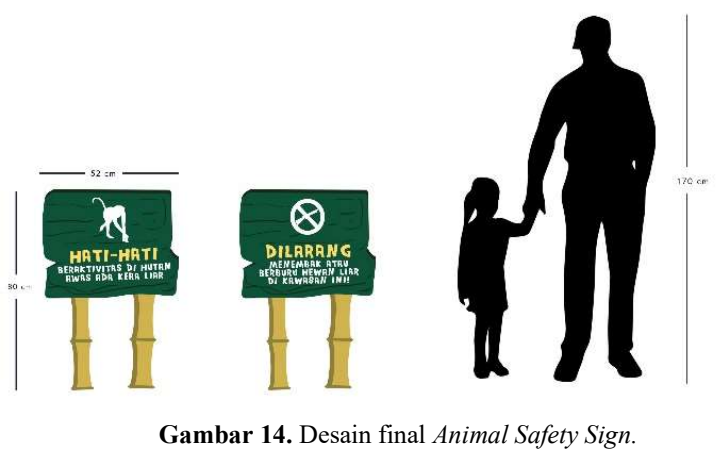

4. Implementasi Desain Gambar 15, 16 dan 17 menunjukkan implementasi desain yang telah dibuat pada objek wisata Exotic Mengare.

\section{IV.KESIMPULAN DAN SARAN}

Exotic Mengare merupakan sebuah objek wisata alam dengan berbagai macam fasilitas yang disajikan didalamnya. Jarak antar wisata satu dengan yang lain cukup jauh, maka penempatan signage di tiap titik sangat penting pada kawasan ini. Permasalahan yang dikaji pada perancangan ini yaitu dengan mendeskripsikan lalu membuat visualisai desain rancangan signage untuk kawasan Exotic Mengare. Output yang di terapkan dalam perancangan ini berupa directional signage, peta wisata, dan animal safety signage dengan rincian spesifikasi pengaplikasian signage yang telah dibuat. Wujud desain tersebut merupakan salah satu alternatif konsep perancangan yang ditawarkan dengan harapan dapat memberi kemudahan wisatawan yang mengunjungi objek wisata untuk mendapatkan informasi

tanpa membuang waktu dengan bertanya tempat yang akan dituju kepada tour guide sehingga dapat meningkatkan kualitas pengalaman yang didapatkan. Selain itu, penempatan signage yang tepat dapat membuat signage lebih terlihat dan berfungsi secara maksimal. 
Semasa mengerjakan perancangan signage, ditemukan masih banyak hal yang harus disusun secara bertahap untuk membenahi proses perancangan dan membutuhkan riset yang mendalam agar bisa menyelesaikan permasalahan yang ada. Maka saran yang ingin disampaikan mengenai perancangan signage Exotic Mengare antara lain, perlu adanya papan informasi seperti nama satwa atau tumbuhan, papan peringatan zona berbahaya, dan papan himbauan seperti menjaga kebersihan. Potensi besar yang diberikan objek wista ini juga dapat menjadi bahan perancangan lain khususnya Desain Komunikasi Visual untuk membuat media promosi, maupun merchandise guna menambah jumlah wisatawan dan mampu bersaing dengan objek wisata serupa.

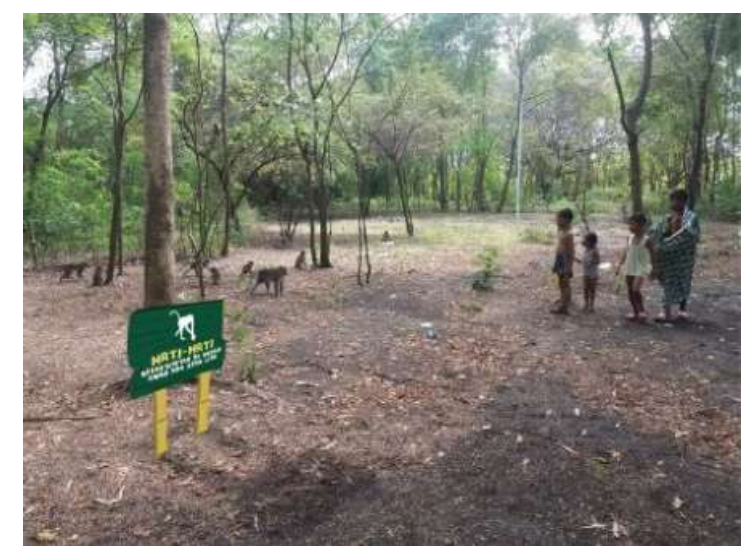

Gambar 15. Implementasi desain pada kawasan hutan dan area camping ground.

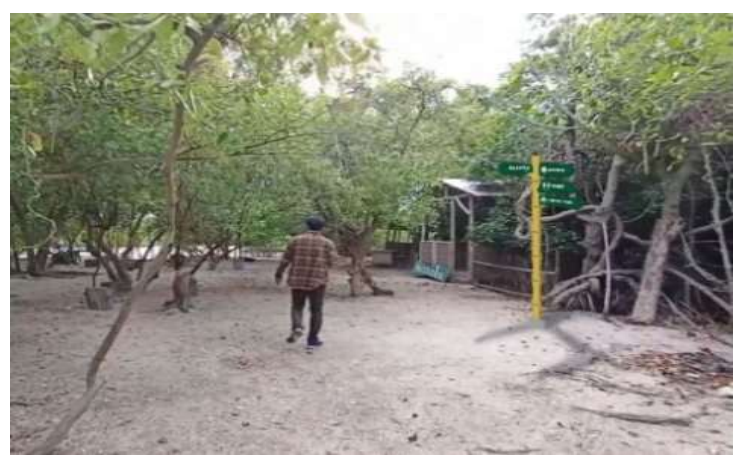

Gambar 16. Implementasi desain pada area pantai ayang-ayang dan spot jualan.

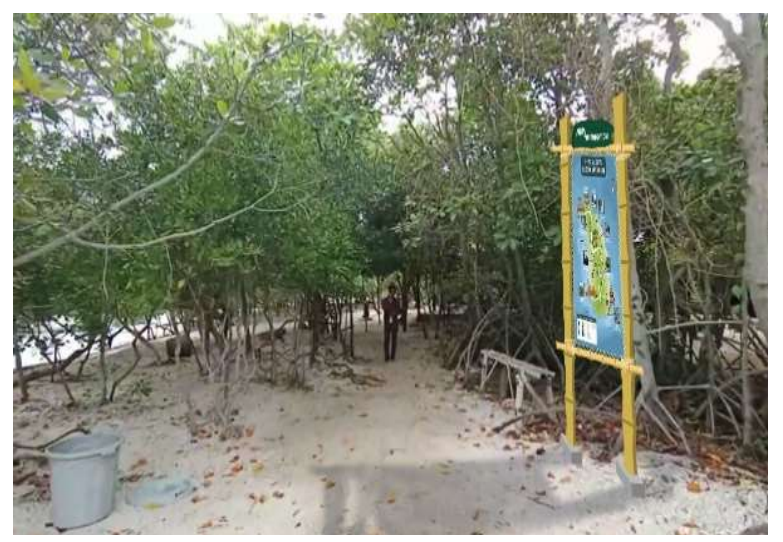

Gambar 17. Implementasi desain pada area pintu masuk wisatawan

\section{DAFTAR PUSTAKA}

[1] Putri, D., Bahruddin, M. and Khoiriqqoh, A., 2016. Perancangan Logo dan Media Promosi Pulau Mengare Gresik Berbasis Edukasi sebagai Upaya Mengenalkan Wisata Sejarah. Jurnal Art Nouveau, 5(1), p.1.

[2] NAIIM, N. (2019). Potensi Kawasan Mangrove Sebagai Ekowisata di Pulau Mengare Kabupaten Gresik (Doctoral dissertation, Universitas Gadjah Mada).

[3] Kusrianto, Adi. 2010. Pengantar Tipografi. Jakarta: Elex Media Komputindo. p23.

[4] Tinarbuko, Sumbo. 2012. Semiotika Komunikasi Visual. Yogyakarta: Jalasutra. p12.

[5] Miazaki, R. B., \& Setyadi, D. I. (2020). Perancangan Desain Grafis Lingkungan Museum Maritim Surabaya North Quay di Pelabuhan Tanjung Perak Surabaya. Jurnal Sains dan Seni ITS, 8(2), F294-F299.

[6] Soewardikoen, D. W. (2019). Metodologi Penelitian: Desain Komunikasi Visual. PT Kanisius.

[7] Prajarini, D., 2020. Perancangan Prototype Web Profile Desa Wisata Dan Kerajinan Gamplong Sleman Dengan Metode Desain User Experience. AKSA: JURNAL DESAIN KOMUNIKASI VISUAL, 2(1), pp.249-259.

[8] HALIMI, A. N. (2015). Perancangan Sign System Kawasan Wisata Besuki Kediri. Jurnal Seni Rupa, 3(2).

[9] Aristantie, F. (2011). Perancangan Sign System Taman Satwa Taru Jurug.

[10] Supriyono, R. (2010). Desain Komunikasi Visual. Teori dan Aplikasi. Yogyakarta: Andi.

[11] Kautsar, M. A., \& Indrayana, D. (2012). Perancangan Environmental Graphic Design Kebun Binatang Surabaya dengan Konsep Uniquely Playful. Jurnal Sains dan Seni ITS, 1(1), F66-F71.

[12] Subianto, I., Anto, P. and Akbar, T., 2018. Perancangan Poster sebagai Media Edukasi Peserta Didik. Jurnal Desain, 5(03), p.215.

[13] Sunarya, L., Dermawan, O., \& Amrullah, M. H. (2016). Desain Media Sign System dan Himbauan sebagai Penunjang Informasi pada Yayasan Perguruan Islam Attaqwa. Journal Sensi, 2(1), 58-69. 